\title{
$\triangle \mathrm{IA}$ TI $Ф \mathrm{I} \Lambda \mathrm{\Omega} Ф \Omega T E P O N$ KAI $\Sigma \Pi O \Upsilon \triangle$ AIOTEPON $\Pi$ OIH $\Sigma$ I $\Sigma$ I $\Sigma$ TOPIA $\Sigma$ E $\Sigma T I N$; In Aristotelis Poeticorum libellum adnotatiuncula*
}

\section{IULIUS DOMAŃSKI / Varsovia/}

Ea, quae in nono Aristotelis Poeticorum capite de poesi, philosophica sua vi atque natura historiam superante, scripta leguntur, quatenus cum universa Philosophi tum de rerum natura tum de cognitione cohaereant doctrina, quamquam pluribus et vetustioribus et recentissimis abunde explicatur commentationibus ${ }^{1}$, nondum tamen, nisi quid me forte fallit, usquequaque liquet. Quodsi res haec ita sese habet, in animo est quaedam in medium proferre, quae nuper in ea, quae Aristoteles non de poesi, sed de historia senserit, inquirenti ultro sese mihi obtulerunt.

Ac primum quidem, despecta exteriore illa inter poetica metra et prosam orationem intercedente differentia (prosae autem orationis exemplum Herodoti esse opus iam hic operae pretium est animadvertere), propterea poesis ab Aristotele historiae opponitur, quod haec de rebus, quae reapse gestae sunt, narrat, illa de talibus, qualia fieri potuerint secundum verisimile vel secundum necessitatem (1451 a 36-38: oủ tò tà $\gamma \varepsilon v o ́ \mu \varepsilon v a$

* Primum typis impressa est in Pirożyński 1994: 19-25.

${ }^{1}$ Eis fere contentus, quae, cum haec scriberem, praesto inspicere licuit, ad paucissima et hic et infra relego. Cf. Düring 1966: 162; Weil 1960: 168-178; Aristoteles 1974: XVII-XIX. Quibus addere velim etiam Ingarden 1961: 163-233 et 273-285 (magni sane pretii commentationem, cum de imitationis vi atque natura tum de ratione mutua inter poesim et historiam intercedente tractantem, de qua - mihi, dum haec scribebam, etiamtum ignota - Iacobus Sdislaus Lichański certiorem me fecit, quod grato recordor animo: si quis utramque commentationem, Ingardenianam scilicet et meam, inspiciet, in quo eae conveniant in quoque discrepent facile videbit). 


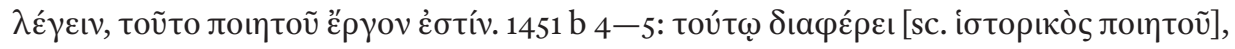

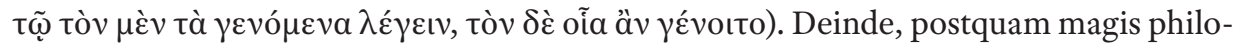
sophicam severioremque sive potius (ut equidem puto) diligentiorem poesi quam histo-

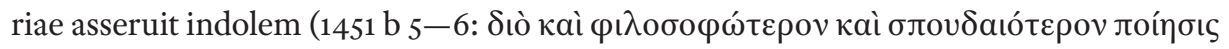
íropías), quasi idem quod prius, sed aliter dicens, addit poesim potius de universali-

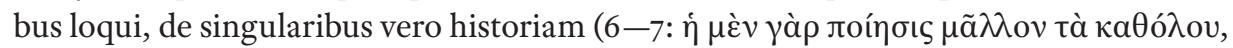

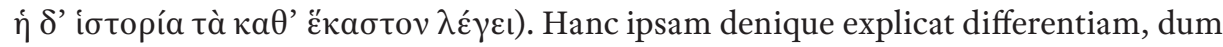
quidnam sit in universum, quidnam singillatim rem narrare, propius definit (8-11:

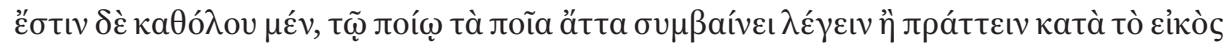

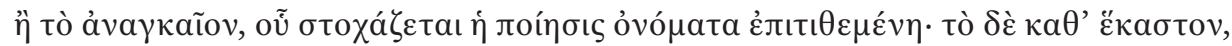

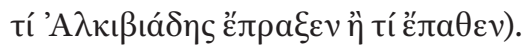

Haec autem omnia quasi $\mathcal{\varepsilon} v \pi \alpha \rho \varepsilon v \theta \varepsilon ́ \sigma \varepsilon$ เ adnotat praemissis in octavo libelli capite non ita paucis de praecipua quadam fabulae, id est narrationis poeticae ( $\tau o \tilde{v} \mu u ́ \theta o v$ ), virtute verbis, nempe de narrationis illius unitate, de qua etiam in sequentibus capitibus inde a decimo in tragoediae inquirens naturam multa facit verba. Quam unitatem in heroico poemate non tum haberi asserit, si de uno quodam heroe narretur, verum tum demum, si ne de uno quidem, quaecumque ille egerit vel quaecumque ipsi acciderint, singillatim dicantur, sed si factorum accidentiumque delectus in narrando ita factus sit, ut fortiore quodam inter se cohaerentia nexu unum quoddam efficere videantur. Eiusmodi autem in narrando unitatem atque cohaerentiam - cui utrumque Homeri poema, ceteroqui rerum peractarum ubertate non carens, diserto in Poeticis est exemplo, cum cyclici illi Homeri imitatores omni in narrando rerum unitate destituti videantur - prudenti cuidam rerum ipsarum narrandarum deberi semper putat delectui, quo fiat, ut non ita omnino narrentur res illae, sicut sese habuerint, sed ita potius, sicut sese habere potuerint, immo et debuerint, et hanc demum ob causam intimo quodam illae inter se adeo in narrando cohaereant nexu, ut ne una quidem privari narratio possit particula, quin tota disturbetur dissolvaturque. De hac vero unitate, itidem Homericae narrationis illustrata exemplo, cum in vicesimo tertio et vicesimo quarto etiam libelli capitibus denuo verba fiunt, denuo tum quoque comparatur poesis historiae illiusque una atque secum usquequaque cohaerens narratio discordanti huius multiplicique atque omnia, quaecumque facta sunt aut

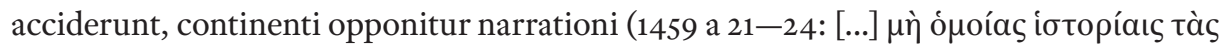

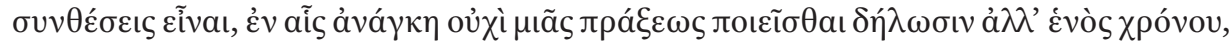

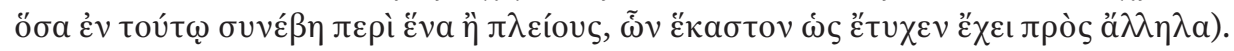
Quae omnia et ipsa per se satis clara sunt, sicut quidem ab Aristotele exponuntur, et ab Aristotelici libelli commentatoribus, coaetaneis nostris praecipue ${ }^{2}$, affatim sunt explicata, ut quidnam imitatio ipsa sit, in qua Aristoteles, Platonem magistrum secutus idemque ab eo dissentiens, omnem artem consistere putabat, vel in primis pateat. Neque enim servilis cuiusdam visa est Aristoteli naturae illa artificialis imitatio aut rudis quaedam rerum naturae reproductio artis esse opus, id quod Plato fere existimasse videtur ${ }^{3}$, sed potius

2 Cf. ex. gr. Aristoteles 1974: 144-145. Cf. etiam Idem 1980: 221-22 et Idem 1988: 308-313.

3 Aristoteles 1974: XIV, Idem 1980: 18-22, Idem 1988: 307-313. 
immutatio quaedam naturalium rerum imitandarum earumque creatrix, ut ita dicam,

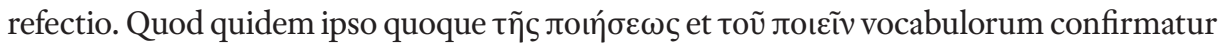
sensu, quo illa ab Aristotele non solum in Poeticis, sed alibi etiam tum adhibentur tum explicantur quoque ${ }^{4}$. Nihil aliud enim Aristoteli ars est nisi ratio quaedam efficiendorum fabricandorumque (factibilia nuncupaverunt posteriores ${ }^{5}$ ), quae autem arte effecta aut fabricata fiunt, non nisi immutatione quadam atque transformatione eorum fieri putat, ex quibus efficiuntur; unde fieri autumat, ut quodcumque arte eficiatur, simile simul et dissimile fiat necesse sit primitivae illi materiae, ex qua sit effectum. Ipsa autem illa immutatio cum in materiae qualicumque formatione, tum vero in superfluorum abiectione consistere Aristoteli videtur. Quo itaque modo sculptor rudi utitur materia, ut hominis vel rei cuiusvis naturalis imitatione oriatur imago, eodem fere universam factorum eorumque quae acciderunt poeta quoque ipsi usurpare videtur materiam, si modo unam sibique ipsi congruentem in ipso est facere narrationem ${ }^{6}$.

Quae cum, ut dixi, satis superque ab Aristotelis Poeticorum commentaribus sint illustrata, nihil iam restat, nisi ut in unum hoc inquiratur, quare idem, quod poeta assequitur, historicus assequi non posse Aristoteli visus sit. Ad quam quaestionem solvendam accedenti tria haec mihi erunt discutienda. Primum ratio quaedam mutua, quae inter Aristotelicas $\tau \tilde{\eta} \varsigma$ лоı́ $\sigma \varepsilon \omega \varsigma$ et historiae intercedat notiones, nondum satis ex eis, quae relata sunt, manifesta; tum eorum, de quibus historicus narrare consuevit, quaenam sit secundum Aristotelis philosophiam natura; postremo principium quoddam e philosophia sumptum, quo Herodotus in historia sua scribenda duci videtur, cum generalissimo quodam philosophandi principio Aristoteli proprio collatum. Haec tria tamen non pro certo quicquam asseverantis aut demonstrantis, sed coniectantis potius et opinantis more tractabo, siquidem tantum abest ut ab ipso Aristotele explicentur, ut pleraque ne significentur quidem, si quae autem quodammodo significentur, longe alio spectare videantur quam ad quaestionem, quam nobis proponimus, solvendam.

Ac primum quidem propterea, opinor, idem quod poeta historicus facere non posse Aristoteli videbatur, quod ne ipsum quidem illud, facere quicquam, hoc est лоเعiv eo sensu usurpatum, quem supra propius definire conati sumus, historici esse posse existimabat. Hunc autem sensum ipsa ceteroquin historiae et historici fatentur nomi-

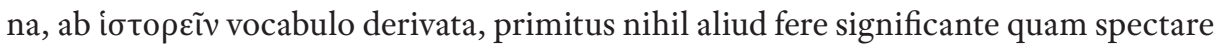
et sciscitare, quaerere et rimari, deinde vero etiam ea, quae spectando rimando quaeren-

${ }^{4}$ Vocabuli sensus, de quo agimus, generatim in lingua Graeca abunde illustratur exemplis in quovis uberiore lexico Graeco cum recentiore tum vetustiore etiam allatis; cf. ex. gr. Pape s.v., et Liddel, Scott s. v. Quoad Aristotelicum sensum speciatim, inspicias velim Eth. Nic. VI 4, 1140 a 1 sqq et Magn. Mor. I 35, 1197 a 3 sqq; cf. etiam Domański 1986: 5-19.

5 Celebrem apud scholasticos medii aevi in mente habeo definitionem illam: „ars est recta ratio factibilium”,

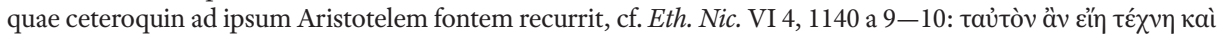

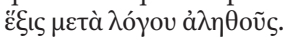

${ }^{6}$ Cf. Poet. 9, 1451 b 28-33, ubi ea, quae reapse gesta sunt, pari modo atque illa a poeta inventa excogita-

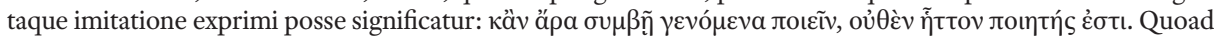
similitudinem, quae inter poetam et sculptorem intercedit, cf. Metaphysicorum libri septimi capita 8-9; cf. etiam Aristoteles 1974: XIV. 
do sciscitando perceperit quis, singillatim et, si ita dici potest, oculatim referre? ${ }^{7}$ Quam vocabulorum horum vim tam diversam et minime Aristotelem latuisse et tum praecipue animo eius obversatam fuisse, cum de discordante inter se poesis et historiae natura in Poeticis semel et iterum dissereret, equidem cum Poeticorum commentatoribus libens accipio $^{8}$. Quod si ita est, non video, quid prohibeat quin illud etiam accipiamus, nihil sane cum artificio, immo ipso cum faciendo, cum $\tau \tilde{\omega}$ лоเعĩv ergo Aristotelicum illum sensum prae se ferente, commune habere Aristoteli visam esse historicam narrationem, sin autem nihil cum faciendo - id est fingendo formandoque - commune habebat, nullo pacto

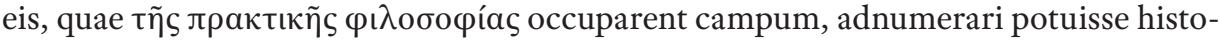
riam, si modo in philosophicis omnino numerari potuisset disciplinis ${ }^{9}$. Certe nusquam ab Aristotele disciplinis illis adnumeratur praeter eum Poeticorum locum, de quo nunc agimus, in quo tamen vix digna aestimatur quae cum philosophia comparetur. Quidnam igitur causae fuisse putemus, cur e vastissimo philosophiae campo ab Aristotele quodammodo tacite exclusa sit?

Nihil aliud in causa fuisse videtur, quare illinc exclusa sit historia, quam ipsa cum humanorum in universum tum praecipue earum rerum ab hominibus gestarum, quae ab historicis inprimis narrari solent, peculiaris quaedam natura. Quas res cum in constantibus stabilibusque et hac ipsa ratione universalibus etiam, dum geruntur, nullo pacto ponendas intellegeret, sed ad ea potius una cum ipsis gerentibus adnumerandas esse,

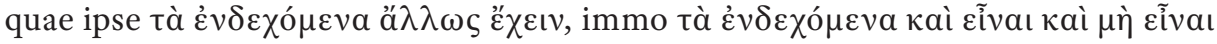
nuncupabat, postquam vero iam gestae sunt, suam inconstantiam instabilitatemque miro quodam modo ita constabilire solitas, ut nullo iam pacto mutari stabilitas illa posset, non ignoraret ${ }^{10}$, consequens erat, ut hoc quoque pro rato acciperet, eodem illas, quo reapse gestae essent et quo a historicis, hoc est "spectantibus", et spectarentur et narrarentur, spectatas et narratas modo neque mente concipi recte posse, sicut stabilia illa constantiaque atque universalia concipiuntur, neque tanto legentes afficere posse gaudio, quanto eos philosophica stabilium constantium universalium afficit speculatio. Haud aliter ergo ipsis quoque rebus reapse gestis delectari legentes posse putabat, nisi si - instar inven-

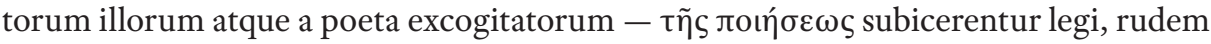
indigestamque propter singularitatem suam fortuitorum factorum humanorum materiam quasi quandam malam texturam ita retexentis, ut contra factorum illorum veritatem superflua quaeque abicerentur, disparata coaptarentur, adunarentur diversa.

Hoc autem philosophico et quidem ex ea potissimum philosophiae parte deducto,

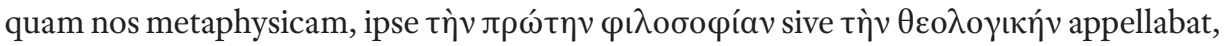

\footnotetext{
7 Quem vocabulorum sensum in universum quodvis lexicon Graecum uberrimis illustrat exemplis; Aristoteli vero proprium in Bonitzii invenies indice (Aristotelis Opera omnia. ed. I. Bekker, vol. V, p. 348 a 60 et b 2-33). Cf. etiam Weil 1960: 89-95.

${ }^{8}$ Aristoteles 1980: 222. Cf. Düring 1966: 422 (n. 135).

9 Quod in Rhet. I 4, 1360 a 37 sqq. historiae cognitio politicae utilis esse dicitur scientiae, id sane ita dicitur, ut manifestum sit historiam adminiculantibus philosophiam practicam adnumerari, ipsi philosophiae politicae non item.
}

${ }^{10}$ Cf. Domański 1986: 12-15. 
non ideo Aristoteles in historia aestimanda usus esse videtur criterio, quod ea iudicandi ratione duceretur, quam hodie aprioristicam nuncupares, sed propterea potius, quia in irritum redactum esse aestimabat permagnum Herodoti laborem, eo videlicet consilio a historiographiae Graecae patre illo susceptum, ut unam quandam simplicemque ostenderet rationem, qua res tum ab hominibus singulis tum a populis quoque geri putabat. Id videlicet egit Herodotus, ut divina quadam atque sapienti res illas regi iustitia demonstraret, iustitiam autem ipsam, id quod iam dudum perspectum est ${ }^{11}$, sicut $\lambda$ ó $\gamma o v$ quendam mente concepit eumque, praedecessorum suorum, praesertim vero Hecataei, meris sese opponens narratiunculis, ad veterum philosophorum sive potius, ut ipsi interdum sese appellare solebant, physiologorum, id est naturae scrutatorum, conformavit doctrinas, Heracliti imprimis, cui ego Anaximandrum quoque libens adicio. Iustitiam enim illam, divinae cuidam providentiae debitam, qua res ab homnibus gestas regi autumabat, non solum quasi quadam contrariorum harmonia sive aequilibrio constare coni-

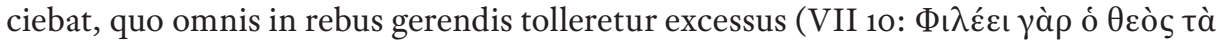

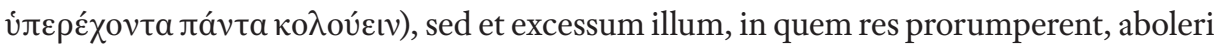
et rerum aequilibrium quoque, divina providentia iustitiaque restitui solitum, ad instar eorum, quae in materialum rerum natura fiunt, imaginabatur, quidnam aliud secutus nisi

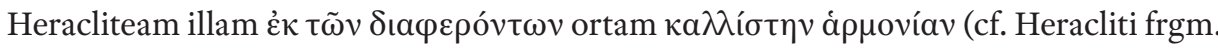

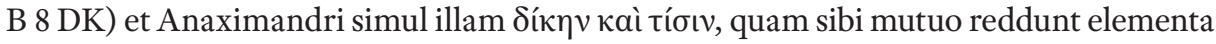
(cf. Anaximandri frgm. B 1 DK) ${ }^{12}$ ? Quod si ita est, idem ad res ab hominibus gestas explicandas transtulisse videtur Herodotus principium, quo naturam regi et Anaximander Milesius et Heraclitus Ephesius asseverabant et quod Anaximander poenae et vindictae propius difinivit nominibus, a rebus humanis ad res naturae appellandas translatis, prope eisdem videlicet, quibus Herodotus postea rerum humanarum gerendarum descripsit principium.

Si quis autem quaeret, quare eiusmodi $\lambda$ ó $\gamma$ o ad res gestas explicandas a Herodoto adhibitus Aristoteli non placuerit, ego ad generalisimam quandam philosophandi rationem Aristoteli propriam et a priscorum philosophorum ratione toto caelo differentem provocabo. Neque enim unam quandam eandemque unicam eorum, quae stabilia constantiaque vere perpetuoque sunt, et eorum, quae, utpote instabilia fortuitaque, esse et non esse possunt, ả $\rho \chi \eta ́ v$ illam sive principium vetustissimorum philosophorum admittebat neque unam eandemque utrorumque cognoscendorum explicandorumque rationem. Immo contra philosophorum illorum morem, quos recte "monistas" recentiore Latinitatique insueto nuncupares nomine, cum in eis, quae aliter esse non possunt, duo quaedam distinxit genera - caelestium alterum, divinius illud quidem neque casui ulli aut fortunae subiectum, alterum terrestrium quadamtenus fortuitorum ${ }^{13}-$ tum vero $^{2}$ peculiare quoddam humanarum rerum libertate insignium ab utroque illo rerum natu-

11 Cochrane 1957: 457-468 (praesertim vero pp. 460-462).

12 Herodotum Anaximandri vestigia pressisse animadvertit iam ante sexaginta hos annos Sinko 1932: 171.

13 Eandem Aristoteli visa esse servare naturam quae gesta sunt atque quae geruntur, inde conicio, quod, cum 1451 a 36 tà $\gamma \varepsilon v o ́ \mu \varepsilon v a$ occurrant, mox idem prorsus signifiantia habemus tà $\gamma \varepsilon v o ́ \mu \varepsilon v a ~(1451$ b 29, 34:

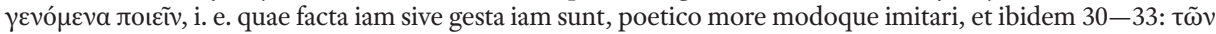


ralium genere segregavit genus, post monistas illos vetustissimos et posteriores dualistas (velunt erant Democritus altera et Plato altera ex parte) verus sane pluralismi (iterum subbarbaro nomine mihi nuncupandi, aliud enim non invenio) ac praecipuus sane antistes. Accedit, quod res illae humanae nulla omnino divina providentia regi Aristoteli

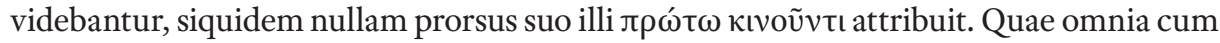
ita essent, fieri utique potuit, ut neque illam a Milesio Anaximandro naturae adscrip-

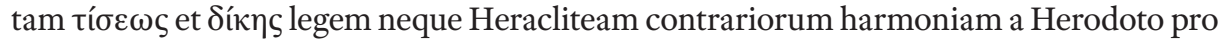
rerum a hominibus gestarum ratione usurpatam recte ab ipso usurpatam esse iudicaverit, immo nullum omnino in rebus humanis, sicuti quidem ipsae ex se fiunt, certum esse posse principium, necessitati videlicet stabilitatique cuidam immotae subiectum, acceperit neque aliter in iis, sicut ipsae ex se fiunt, narrandis principium eiusmodi adhiberi posse autumatus sit, nisi si per poeticam artem, quam non speculativae, sed practicae et productivae sive potius creatrici assignavit philosophiae, immutarentur et ad eorum, quae aliter esse non possunt, necessitati constantiaeque subiectam rationem quodammodo a poeta revocarentur. Etenim, opinor, ita demum res humanae eam induere posse speciem Aristoteli videbantur, qua divinis naturae rebus quodammodo redderentur similes ideoque gaudio etiam afficere possent mentem humanam, non nisi eis, quae oủ

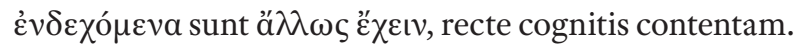

Sic mihi quidem reficienda atque restituenda videtur esse via, quae Aristotelem ad illam magis philosophicam magisque diligentem poesis quam historiae naturam in Poeticorum libello asserendam perduxit. Quam viam si coniectantis opinantisque potius quam quicquam pro certo asseverantis more quadamtenus illustrare contigit, satis ad tempus videor fecisse.

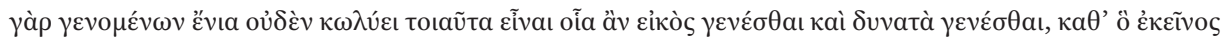

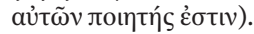




\section{CONSPECTUS LIBRORUM}

Aristoteles, 1974, Dell'arte poetica, ed. C. Gallavotti, Milano.

Aristoteles, 1980, La poétique, ed. R. Dupont-Roc et J. Lallot, Paris.

Aristoteles, 1988, Arystoteles. Retoryka, Poetyka, transl., H. Podbielski, Warszawa.

Cochrane, C.N., 1957, Christianity and Classical Culture. A Study of Thought and Action from Augustus to Augustine, New York.

Croix, G. E. M., 1992, „Aristotle on History and Poetry (Poetics 9, 1451a36 - b11)”, in: A. O. Rorty (ed.), Essays on Aristotle's Poetics, Princeton, pp. 3-32.

Domański, J., 1986, „Przygodność, zmienność, wolność. Glosa do Etyki nikomachejskiej Arystotelesa”, Przegląd Tomistyczny 2, pp. 5-19.

DüRING, I., 1966, Aristoteles. Darstellung und Interpretation seines Denkens, Heidelberg.

Gastaldi, S., 1973, „Poesia e historia nella Poetica aristotelica”, Rediconti dell’ Istituto Lombardo di Scienze e Lettere 107, pp. 202-242.

INGARDEN, R., 1961, A Marginal Commentary on Aristotle's Poetics, New York.

INGARDEN, R., 1966, „Uwagi na marginesie 'Poetyki’ Arystotelesa”, in: Idem, Studia z estetyki, t. I, Warszawa, pp. $337-377$.

LidDEL, H.C., Scott, R., 1953, A Greek-English Lexicon, Oxford.

PAPE, W., 1888, Griechisch-deutsches Handwörterbuch, Braunschweig.

PIRożý́ski, J. (ED.), 1994, Beiträge der polnischen Stipendiaten der Herzog August Bibliothek zur Philosophie, Geschichte und Philologie, Kraków.

SINKo, T., 1932, Literatura grecka, t.1, Kraków.

WeIL, R., 1960, Aristote et l'histoire. Essai sur la "Politique”, Paris.

I U L I US DOM A ŃSK I

/Varsovia /

A B STR ACT

\section{Why Is Poetry More Philosophical Than History? Some Remarks On Aristotle's Poetics}

Aristotle's statement that - in terms of philosophy - poetry is superior to history can be understood better, when analysed in the context of the Stagirite's epistemology, ontology, and eudaimonic ethics. Both poetry and history deal with numerous contingent and chaotic events, but while history is only reconstructive, poetry reworks its matter more thoroughly. History attempts to recount all events and does it in accord with their contingent and chaotic nature, whereas poetry implies certain choices. By doing so, it introduces uniformity and coherence thus providing a different ontic status than the one that reigned originally. Consequently, the cognitive result of poetry can be compared to the beatific value of conceptual knowledge in philosophy.

Aristotle, poetry, rhetoric, history, philosophy 